\title{
Oral Ibandronate Therapy in Three Patients with Osteogenesis Imperfecta
}

\author{
Štěpán Kutílek ${ }^{1,2,3, *}$, Ivana Plášilová2,3, Sylva Skálová3, Milan Bayer, ${ }^{3,4}$, Erika Ondrušová3
}

\begin{abstract}
Introduction: Treatment with orally administered ibandronate is an effective way to increase bone mineral density (BMD) and reduce fracture rate in post-menopausal women and in men with osteoporosis. There are only very few reports concerning ibandronate therapy in children and adolescents, and in patients with osteogenesis imperfecta (OI), as bisphosphonates are not registered for therapeutic use in pediatrics.

Case Report: We present three patients with OI, where once-monthly oral ibandronate increased spinal BMD after two and four years, respectively, of therapy without any occurrence of new fractures and no adverse reactions. Somatic growth was not affected by the ibandronate treatment.

Conclusion: Once-monthly oral ibandronate increased BMD and most probably improved bone quality in young patients with OI.

\section{KEYWORDS}

ibandronate; osteogenesis imperfecta; bone mineral density

\section{AUTHOR AFFILIATIONS}

${ }^{1}$ Department of Pediatrics, Klatovy Hospital, Klatovy, Czech Republic

${ }^{2}$ Department of Pediatrics, Pardubice Hospital, Pardubice, Czech Republic

${ }^{3}$ Department of Pediatrics, Faculty of Medicine and Faculty Hospital in Hradec Králové, Charles University, Hradec Králové, Czech Republic

${ }^{4}$ Department of Pediatrics, 3rd Faculty of Medicine and University Hospital Královské Vinohrady, Charles University in Prague, Czech Republic

* Corresponding author: Department of Pediatrics, Klatovy Hospital, Klatovy, Czech Republic; e-mail: kutilek@nemkt.cz
\end{abstract}

Received: 13 December 2019

Accepted: 12 August 2021

Published online: 11 November 2021

Acta Medica (Hradec Králové) 2021; 64(3): 187-192

https://doi.org/10.14712/18059694.2021.32

(c) 2021 The Authors. This is an open-access article distributed under the terms of the Creative Commons Attribution License (http://creativecommons.org/licenses/by/4.0), which permits unrestricted use, distribution, and reproduction in any medium, provided the original author and source are credited. 


\section{INTRODUCTION}

Osteogenesis imperfecta (OI) is a group of genetic skeletal disorders with high bone turnover, low bone mass and increased bone fragility with multiple low-energy trauma fractures. Bisphosphonates, such as intravenous pamidronate or zoledronate, oral alendronate or risedronate are used to increase bone mineral density and reduce number of fractures in patients with OI $(1,2)$, several studies also reported improved function and mobility after bisphosphonate treatment (1-3).

Ibandronate, an effective antiresorptive agent, is widely used in the treatment of postmenopausal and male osteoporosis $(4,5)$. So far, it has been only scarcely used in children with low bone mineral density (BMD) and recurrent fractures (6-11). We present three patients with OI treated with once monthly oral ibandronate.

\section{CASE REPORTS}

\section{CASE REPORT 1}

The first patient was a male with type IV OI, based on clinical features (recurrent fractures, blue sclerae, dentinogenesis imperfecta, stunted growth, hyperkyphosis of the thoracic spine, long bone deformities). His father was also suffering from OI, with multiple fractures of the extremities and vertebrae. Our patient suffered 40 low-energy trauma fractures until the age of 11 years (i.e. mean 3.6 fractures/year) (Figure 1a). Afterwards, he was started on weekly oral $70 \mathrm{mg}$ alendronate, together with calcium and vitamin $\mathrm{D}$. This treatment, performed at a different healthcare facility, translated into a rapid drop in number of fractures and impressive increase in spinal BMD (Figure la, b). After nine years of treatment, alendronate was discontinued, due to occassional gastrointestinal discomfort (heartburn) and possible risks of long term bisphosphonate therapy (potential risks of jaw osteonecrosis and atypical femoral fractures). After the withdrawal of alendronate, alleviation of heartburn followed. However, after 12 months of drug holliday, at the age of 21 years, he complained about severe pain in the extremities and backpain. X-rays did not reveal any signs of atypical femoral fractures, neither new vertebral fractures. There was a $5 \%$ drop in spinal bone mineral density (L1-L4 BMD; $\mathrm{g} / \mathrm{cm}^{2}$; DXA Lunar), and in relevant Z-score (Figure 1b). Shortly afterwards he suffered a low-energy trauma fracture of the right tibia, infraction of the 5th metacarpal bone of the right hand and fracture of the rib after an episode of coughing. He was restarted on bisphosphonates, this time on oral ibandronate ( $150 \mathrm{mg}$ tablet) once monthly. He was also receiving oral calcium (1000-1500 mg/day) and vitamin D (cholecalciferol 1000-1500 IU/day). This was followed by an alleviation of pain within two months and another increase in spinal BMD $\left(\mathrm{g} / \mathrm{cm}^{2}\right)$ after one $(+4.1 \%)$ and two years $(+6.5 \%)$, respectively, and a corresponding increase in Z-score (Figure 1b). Blood count, basic biochemical parameters (serum levels of sodium - S-Na, potassium - S-K, chloride - S-Cl, calcium - S-Ca, phosphate - S-P, magnesium - S-Mg, creatinine, parathyroid hormone S-PTH and activity of alkaline phosphatase - S-ALP, aspartate-aminotransferase - S-AST, alanin-aminotransferase $\mathrm{S}$-ALT, urinary calcium/creatinine ratio - U-Ca/U-creat and serum bone turnover markers osteocalcin - S-OC and crosslinked C-terminal telopeptide - S-CTx) were evaluated every three months. These were within normal reference ranges. In the course of ibandronate treatment there was no significant shift in laboratory markers and we noticed oscillating values of S-OC, CTx. No new fractures occurred (Fig. 1a), he did not experience any adverse events.

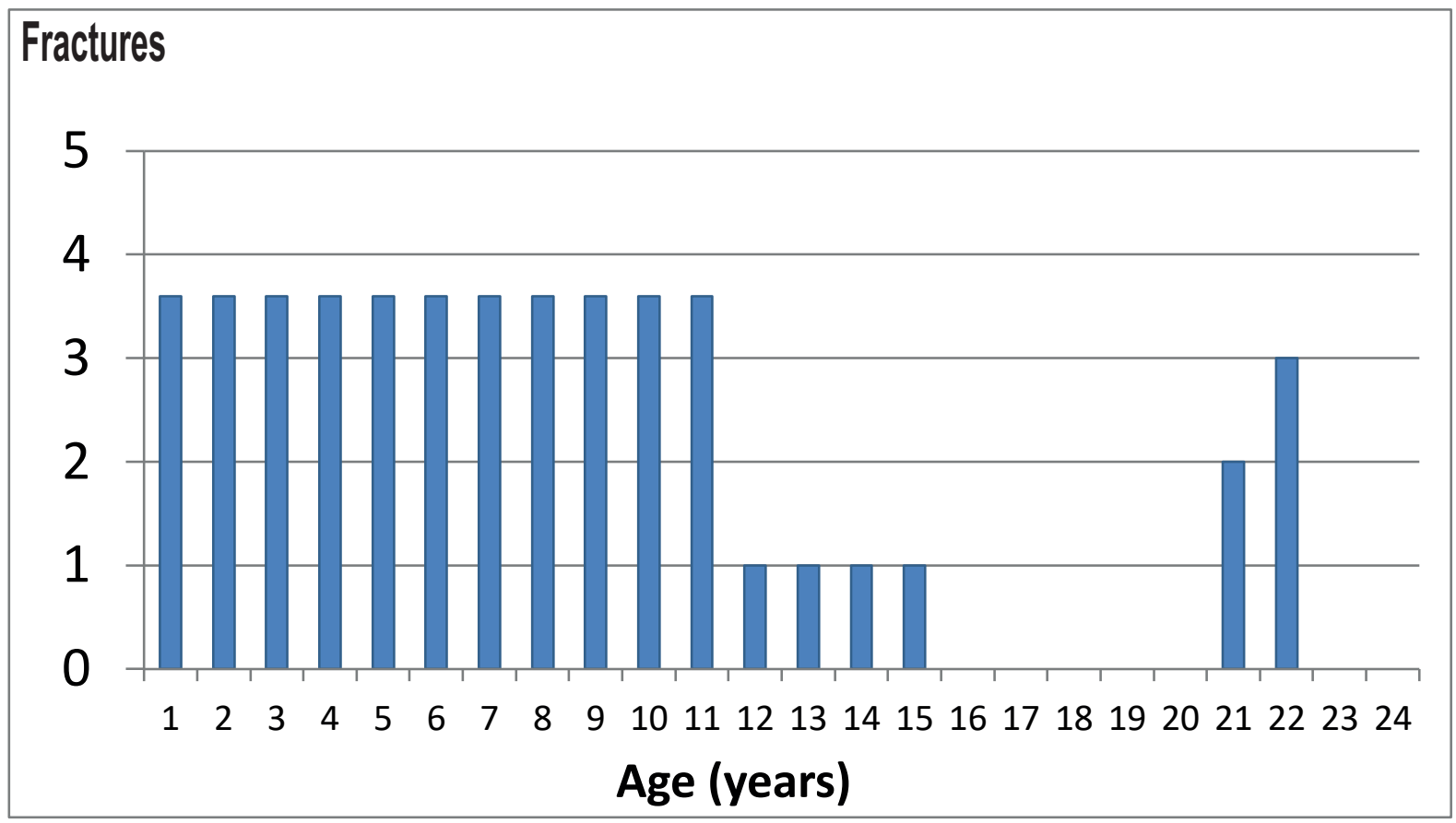

Fig. 1a Changes in the number of low-energy trauma fractures in patient No. 1 The patient suffered 40 fractures until the age of 11 years, i.e. average 3.6 fractrues per year. Alendronate treatment between the age of 12 and 20 years and ibandronate therapy between year 22 and 24 , respectively. 


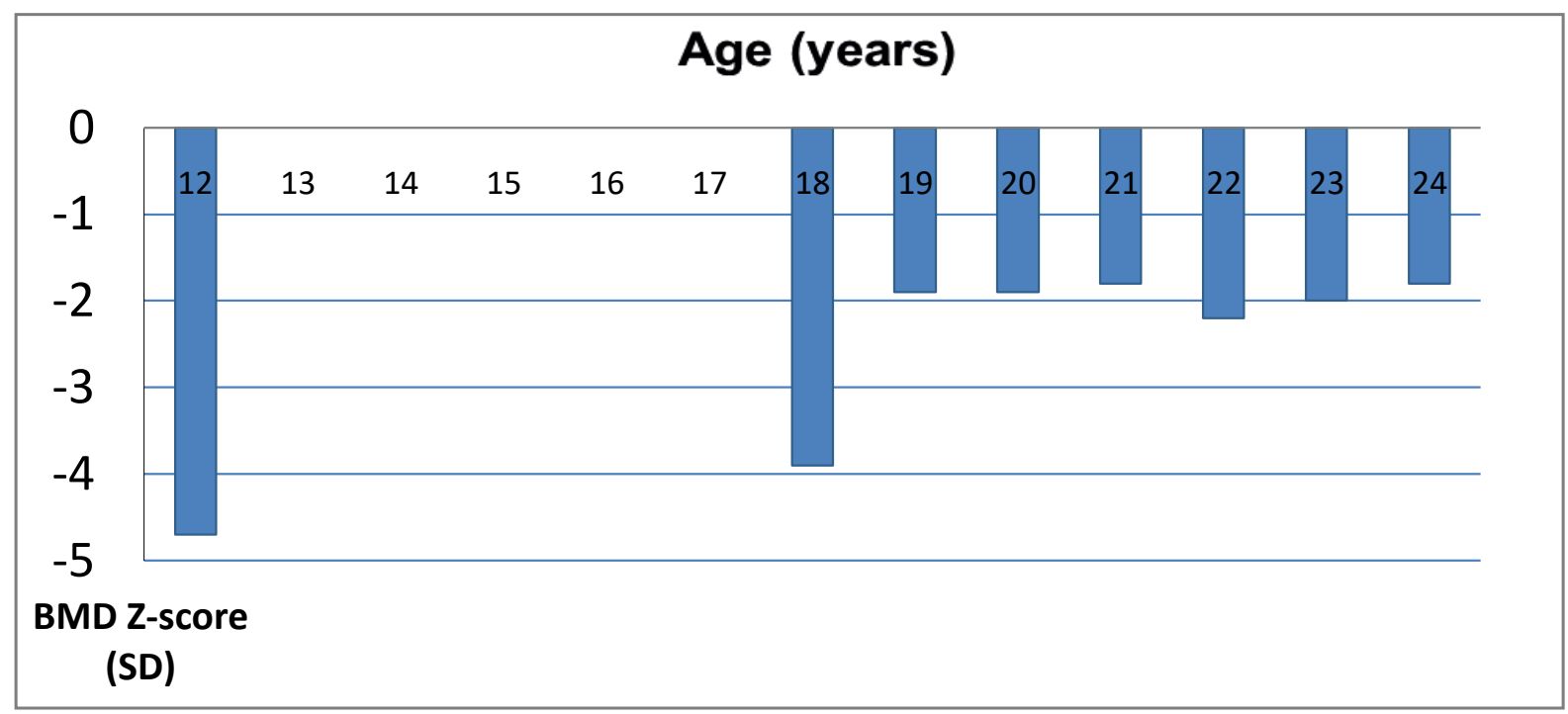

Fig. 1b Changes in spinal (L1-L4) bone mineral density (BMD; Z-score) in patient No. 1 in the course of the alendronate (age 12-20 years) and ibandronate (age 22 onwards) treatment.

\section{CASE REPORT 2}

A 14-year old boy with previous history of resolved nephrolithiasis and hypercalciuria in infancy and a low-energy trauma fracture of the second lumbar vertebra at the age of 13 years (Figure 2a). Body height was $154 \mathrm{~cm}$ (-1.9 SD $\mathrm{Z}$-score); weight $37 \mathrm{~kg}$ (-1.8 SD Z-score); body mass index (BMI) 15.6 (-1.6 SD Z-score). The boy was previously diagnosed with attention deficit hyperactivity disorder (ADHD) and obsessive-compulsive disorder (OCD), and was taking clomipramin and methylphenidate, previous medication included atomoxetine.

He had triangular face, enamel tooth defects, blue sclerae, muscular hypotonia, joint and skin hyperlaxity. L1-L4 BMD was very low (0.553g/ $\mathrm{cm}^{2}$; Z-score -5.1 SD) (Figure $2 \mathrm{~b}$ ). Celiac disease, inflammatory bowel disease, hyperthyroid- ism, osteomalacia/rickets, parathyroid disorders and renal insufficiency were all ruled out by laboratory assessment. Blood count and biochemical parameters (S-Na, S-K, S-Cl, S-Ca, S-P, S-Mg, S-creatinine, S-PTH, S-ALP, S-AST, S-ALT, $\mathrm{U}-\mathrm{Ca} / \mathrm{U}$-creat) were all within normal reference ranges. He fulfilled the clinical criteria for OI type I. Informed consent from the patient and his parents was obtained and he was started on once monthly oral ibandronate (150 mg/tablet), at the age of 14 years and 6 months. He was also receiving oral calcium (1000-1500 mg/day) and cholecalciferol 1000-1500 IU/day. The drugs were applied by his parents. After four months his spinal BMD $\left(\mathrm{g} / \mathrm{cm}^{2}\right)$ increased by $13 \%$, together with an increase in relevant Z-score; (Figure $2 \mathrm{~b}$ ) and after further nine months (i.e. 13 months of treatment) we noticed a dramatic increase in his BMD by $41 \%\left(\mathrm{~g} / \mathrm{cm}^{2}\right)$

\section{Fractures}

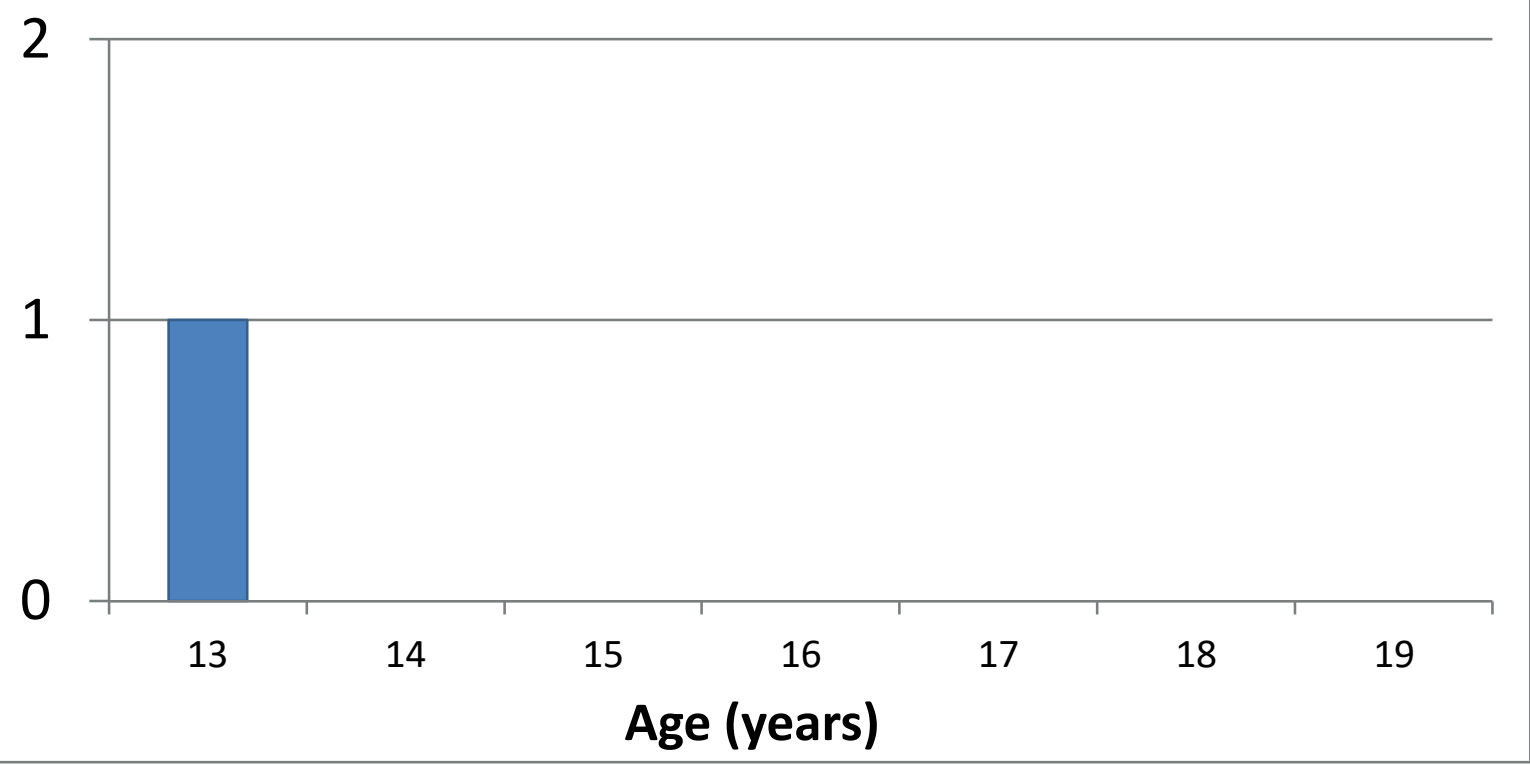

Fig. 2a Number of low-energy trauma fractures in patient No. 2. Ibandronate was administered between the age of 14.5 and 16.8 years. 


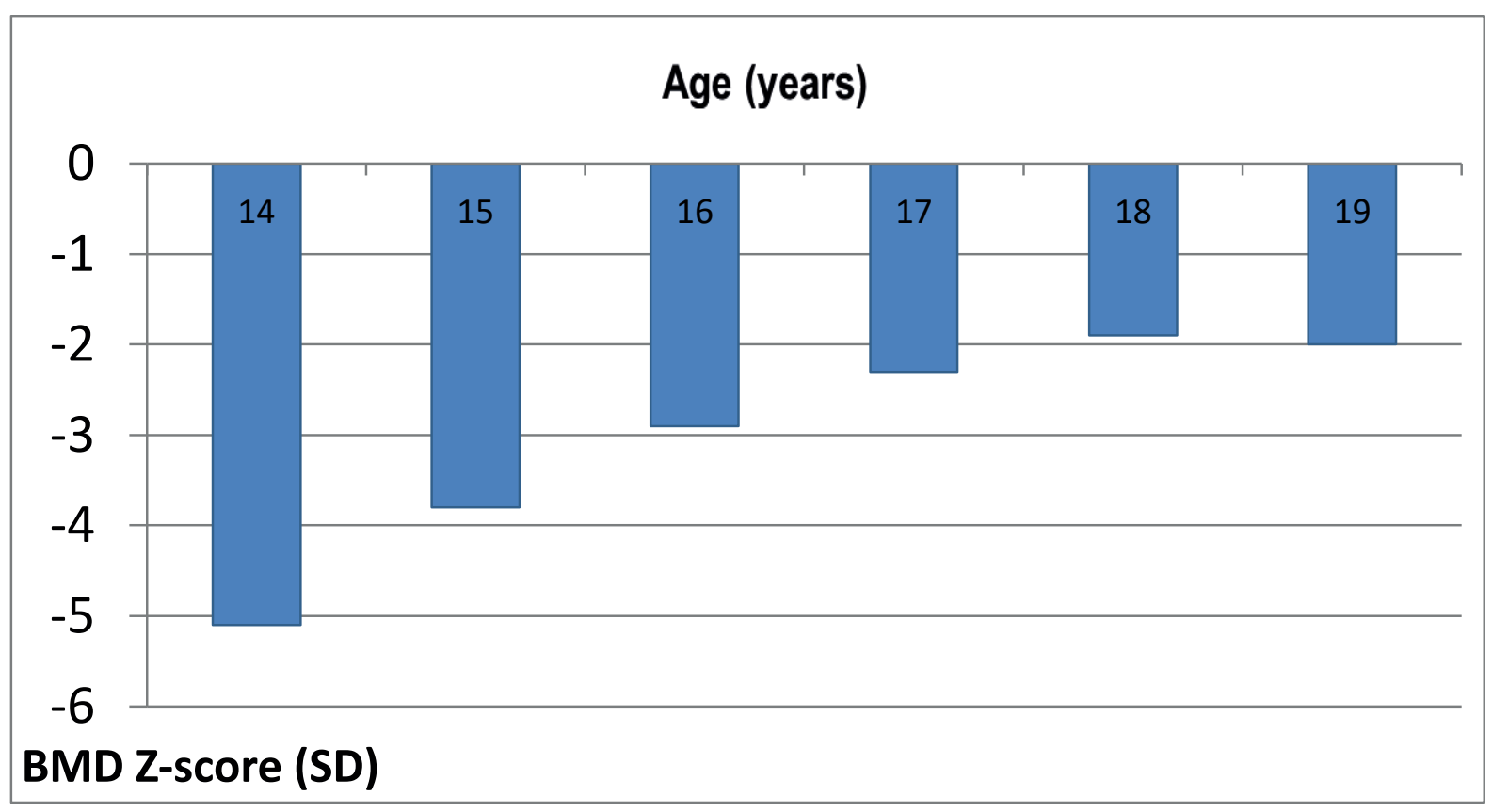

Fig. 2b Changes in L1-L4 BMD (Z-score) in patient No. 2 in the course of the ibandronate treatment. Ibandronate was administered between the age of 14.5 and 16.8 years.

compared to baseline, together with an increase in Z-score (Figure 2b). After another 15 months of ibandronate therapy, there was an additional increase in L1-L4 BMD $\left(\mathrm{g} / \mathrm{cm}^{2}\right)$ of $+13 \%$; in total an increase by $+60 \%$ and a corresponding increase in Z-score after 28 months of ibandronate treatment, when compared to baseline values (Figure $2 \mathrm{~b}$ ). There were no alterations in the biochemical parameters (S-blood urea nitrogen, S-Na, S-K, S-Cl, S-Ca, S-P, S-Mg, S-creatinine, S-PTH, S-ALP, S-AST, S-ALT, U-Ca/U-creat) that were assessed every three months, and no further occurrence of fractures. However, we noticed mild leukopenia on months 12 and 15 (leukocytes 7.8...5.3...6.74...4.5...3.9...3.8...4.3...4.0 $7 \times 10^{9} / \mathrm{L}$; normal $4-10 \times 10^{9} / \mathrm{L}$ ) with a further drop in white blood cells on month 24 and 27, respectively $(3.16 \ldots 2.7 \times$ $\left.10^{9} / \mathrm{L}\right)$. Other blood elements were not affected. Therefore, the patient was also followed-up by a pediatric hematologist since month 14. Ibandronate treatment was discontinued on month 28 , at the age of 16 years and 10 months. We noticed a tendency toward an improvement in white blood cell number on months 32 and 35 (3.08 and $\left.3.26 \times 10^{9} / \mathrm{L}\right)$, respectively. One year later, at the age of 18 years, his L1-L4 BMD $\left(\mathrm{g} / \mathrm{cm}^{2}\right)$ further increased by $9 \%$, with a corresponding increase in Z-score, and at the age of 19 years the L1-L4 BMD remained stable (Figure $2 b$ ). He had no new dental problems, neither gastrointestinal irritation. At the age of 19 years his body height was $174 \mathrm{~cm}$ (-0.9 SD Z-score) and body weight $57 \mathrm{~kg}$ (-1.5 SD Z-score), BMI 18.8 (-1.1 SD Z-score).

\section{CASE REPORT 3}

A girl with blue sclerae, skin and joint laxity, muscular hypotonia, who suffered four low-energy trauma fractures of the limbs between the age of six months and four years (Figure 3a). The diagnosis of OI type I was established on basis of phenotype and personal history by the clinical genetist. Between the age of five and eight years no fractures occurred in spite of low BMD Z-score (Figure 3a, b). At the age of nine years she experienced a left wrist fracture after a minor injury. At the age of 11 years and 6 months years she suffered left acetabular fracture and a left elbow fracture, rerspectively. Body height was then $148 \mathrm{~cm}(-0.3$ SD Z-score), body weight $30 \mathrm{~kg}$ (-1.2 SD Z-score); BMI 13.7 (-1.5 SD Z-score). L1-L4 BMD at the age of 12 years was low (Figure 3b). Blood count and biochemical parameters (S$\mathrm{Na}, \mathrm{S}-\mathrm{K}, \mathrm{S}-\mathrm{Cl}, \mathrm{S}-\mathrm{Ca}, \mathrm{S}-\mathrm{P}, \mathrm{S}-\mathrm{Mg}$, S-creatinine, S-PTH, S-ALP, S-AST, S-ALT, U-Ca/U-creat) were all within normal reference ranges. Informed consent from the patient and her parents was obtained and she was started on oral ibandronate $(150 \mathrm{mg} /$ tablet $)$ once-a-month at 12 years of age. She was also receiving oral calcium (1000-1500 mg/day) and cholecalciferol 1000-1500 IU/day. The drugs were applied by her parents. After one year we noticed a significant L1L4 BMD $\left(\mathrm{g} / \mathrm{cm}^{2}\right)$ increase of $+31 \%$ and a relevant increase in Z-score, and after another year of therapy an additional increase of $+23.8 \%$; in total an increase by $+62 \%$ after two years of ibandronate treatment compared to baseline values. There was also a corresponding increase in Z-score (Figure $3 \mathrm{~b}$ ). There were no alterations in the laboratory parameters (S-blood urea nitrogen, S-Na, S-K, S-Cl, S-Ca, S-P, S-Mg, S-creatinine, S-PTH, S-ALP, S-AST, S-ALT, $\mathrm{U}-\mathrm{Ca} / \mathrm{U}$-creat) that were assessed every three months and no further occurrence of fractures. At the age of 15 years, there was further increase in L1-L4 BMD $(+18 \%$ per year, in total $+92 \%$ compared to the baseline values). A year later (age 16 years), the L1-L4 BMD value $\left(\mathrm{g} / \mathrm{cm}^{2}\right)$ remained stable and unchanged, however with a decrease in Z-score, fortunately within normal reference range (Figure $3 b$ ) and the ibandronate treatment was discontinued. No dental problems occurred, she did not suffer from gastrointestinal irritation. At the age of 16 years her body height was $165 \mathrm{~cm}(-0.2 \mathrm{SD} Z$-score) and body weight $47 \mathrm{~kg}$ (-0.9 SD Z-score), BMI 17.3 (-1.5 SD Z-score). She is still under close surveillance, her BMD to be assessed once-a-year. 


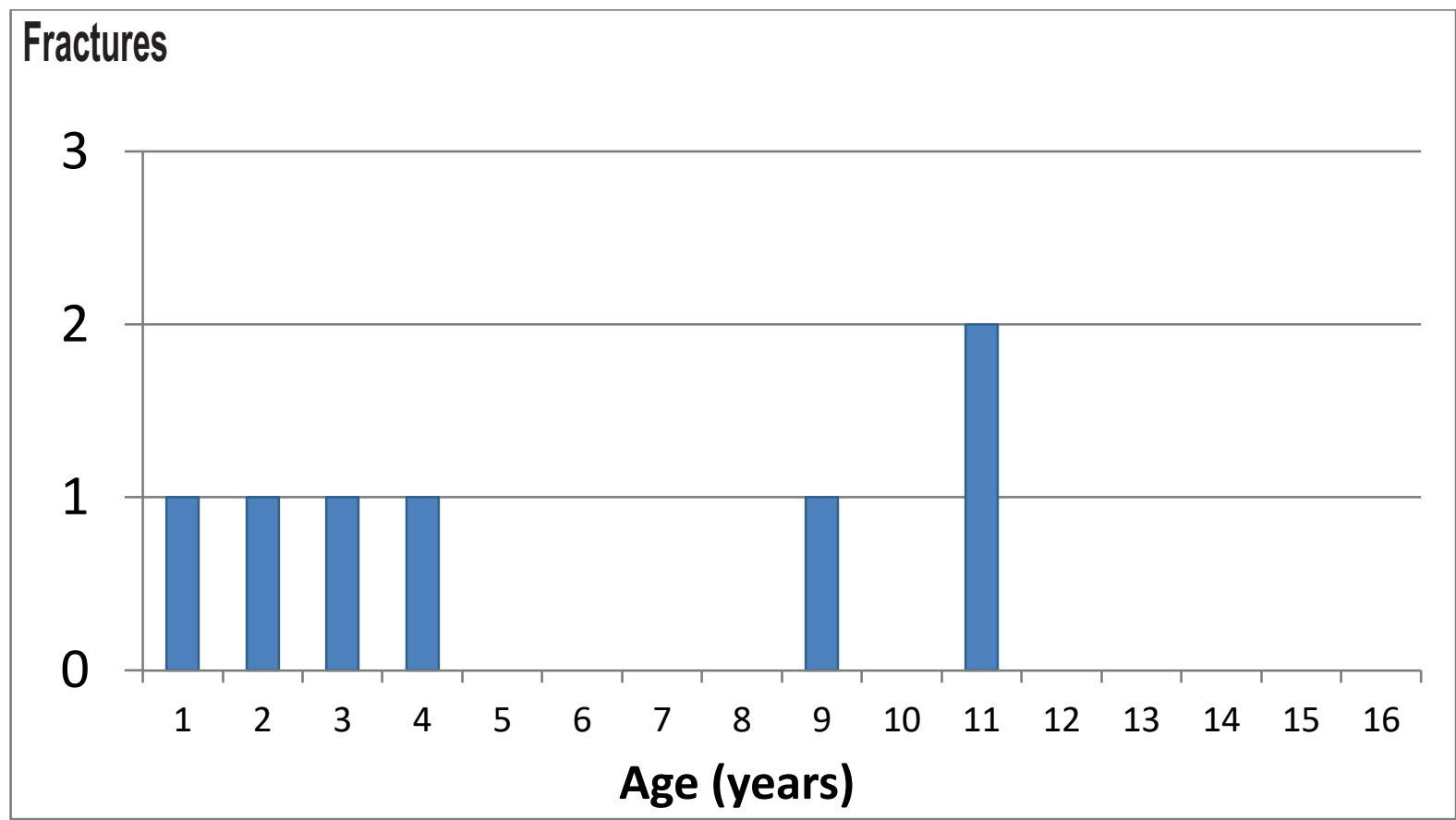

Fig. 3a Number of low-energy trauma fractures in patient No. 3.

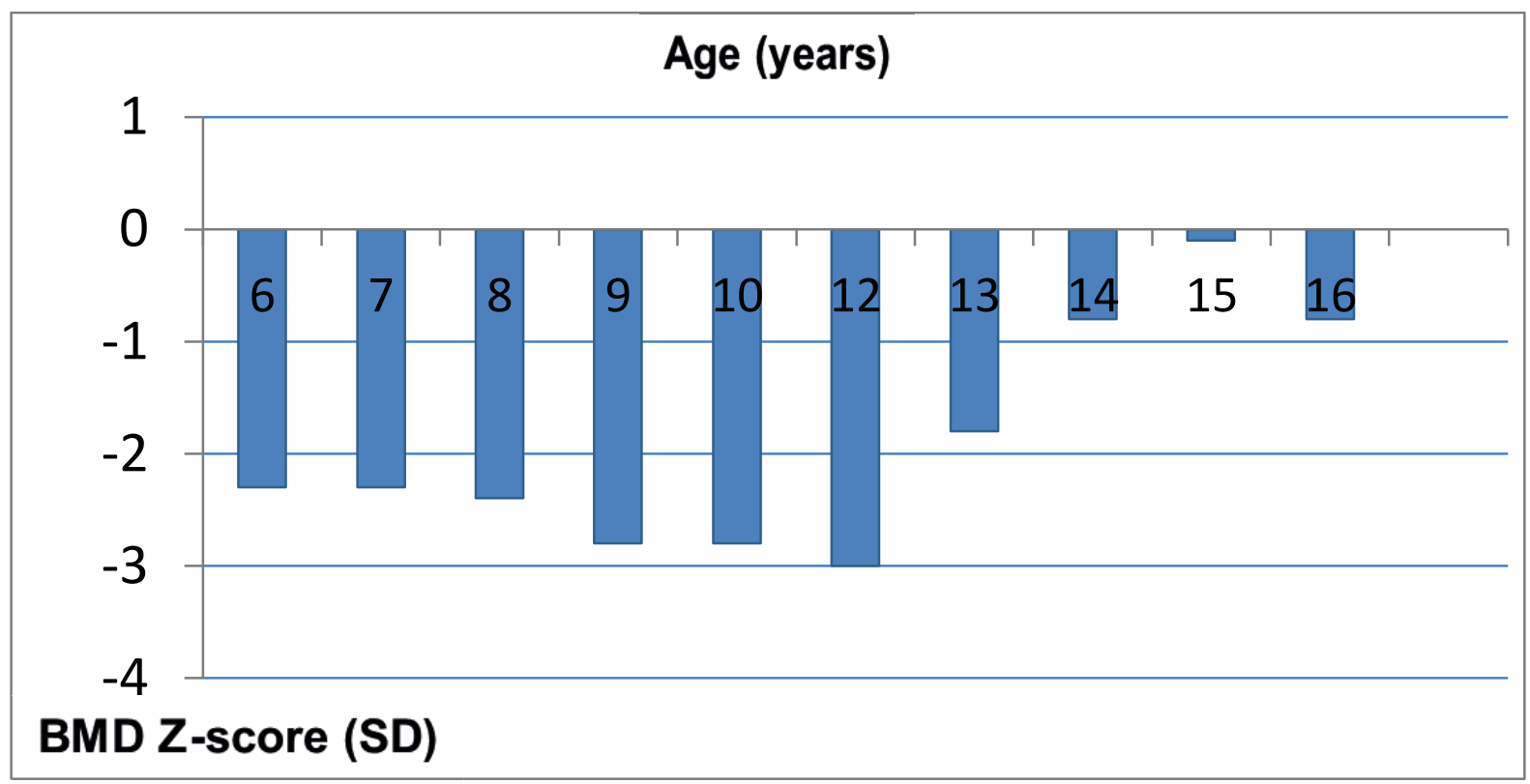

Fig. 3b Changes in L1-L4 BMD (Z-score) in patient No. 3. Ibandronate treatment was started at the age of 12 years, discontinued at the age of 16 years.

\section{DISCUSSION}

Ibandronate is an effective drug in the treatment of postmenopausal and male osteoporosis. There is just one report concerning intravenous (i.v.) ibandronate in the therapy of children with OI, where ibandronate was superior to oral calcitriol (7). In a report by Ipach et al. (8), i.v. ibandronate infused every 3 months to 27 patients with OI had an inhibitory effect on bone turnover markers. We have previously published reports on the beneficial effect of once-montly orally administered ibandronate in children and adolescents with osteoporosis, where one to three years treatment increased spinal BMD and resulted in fracture reduction (10-11). In the current report, our three patients with OI benefited from the ibandronate treatment by means of increased spinal BMD and absence of new fractures. The first patient in this report certainly experienced positive effect of alendronate during the first nine years of bisphosphonate therapy. However, discontinuation of antiresorptive therapy resulted in a drop in BMD and recurrence of fractures, where introduction of ibandronate proved to be a rescue therapy, resulting in an increase in spinal BMD, alleviation of pain and absence of fractures. The other two children with OI were treatment-naive and ibandronate therapy dramatically improved their spinal BMD, as evidenced in absolute values and respective $\mathrm{Z}$-scores (Figures $2 \mathrm{~b}, 3 \mathrm{~b}$ ). Surprisingly, there was no corresponding drop in S-ALP in the course 
of BMD increase. Both patients 2 and 3 give evidence that better treatment effect with bisphosphonates could be expected in patients with more pronounced bone mineral density deterioration. The fact, that L1-L4 BMD further increased and then remained stable even after discontinuation of ibandronate therapy in patient 2 , might confirm the continuous beneficial effect of bisphosphonates on BMD even after the drug withdrawal. Although it is tempting, the impressive increase in L1-L4 BMD can not be solely attributed either to the onset of puberty or the effect of ibandronate. The improvement in BMD is very likely to be the result of bisphosphonate treatment, although puberty must have certainly contributed as well. In patient 3 , the L1-L4 BMD value $\left(\mathrm{g} / \mathrm{cm}^{2}\right)$ at the age of 16 years remained stable and unchanged, but with a decrease in Z-score, however within normal reference range. This annual change in BMD Z-score could be explained by the fact that BMD significantly increases in healthy population in this age and the unchanged absolute value in $\mathrm{g} / \mathrm{cm}^{2}$ translated into a decrease in Z-score. However, in spite of this fact, no new fractues occurred in the observed time period. The ibandronate treatment did not adversely affect the patients'growth velocity, as evidenced by the basic anthropometric data.

Leukopenia and agranulocytosis has been observed after intravenously administered zoledronate (12). Concerning leukopenia in patient No. 2, we can't rule out the role of ibandronate therapy in this adverse event, however clomipramin and methylphenidate medication could have contributed as well. Previously, changes in white blood count have been repeatedly reported after clomipramin $(13,14)$ and methylphenidate medication (15), respectively, but never after ibandronate. Due to safety issues and due to the fact that patient's BMD was steadily improving and almost reached the low-normal level of -2 SD Z-score, we decided to discontinue the ibandronate therapy and opted for drug holiday.

In conclusion, once-monthly oral ibandronate increased BMD and most probably improved bone quality in young patients with OI. Ibandronate, as well as other antiresorptive bone drugs, is an off-label drug and should be used only in the context of an established clinical program with specialist consultation $(1,2,10,11)$.

\section{ACKNOWLEDGEMENTS}

This work was presented at The 9th International Conference on Children's Bone Health (ICCBH), June 22-25 2019; Salzburg, Austria.

\section{REFERENCES}

1. Sam JE, Dharmalingam M. Osteogenesis imperfecta Indian J Endocr Metab 2017; 21: 903-8.

2. Dwan K, Phillipi CA, Steiner RD, Basel D.Bisphosphonate therapy for osteogenesis imperfecta. Cochrane Database Syst Rev 2016 Oct 19; 10:CD005088

3. Constantino CS, Krzak JJ, Fial AV, et al. Effect of bisphosphonates on function and mobility among children with osteogenesis imperfecta: A systematic review. J Bone Miner Res PLUS 2019; 3/10: e10216.

4. Reginster JY, Adami S, Lakatos P, et al. Efficacy and tolerability of once-monthly oral ibandronate in postmenopausal osteoporosis: 2 year results from the MOBILE study. Ann Rheum Dis 2006; 65: 654-61.

5. Orwoll ES, Binkley NC, Lewiecki EM, Gruntmanis U, Fries MA, Dasic G. Efficacy and safety of monthly ibandronate in men with low bone density. Bone 2010; 46(4): 970-6.

6. Cundy T, Wheadon L, King A. Treatment of idiopathic hyperphosphatasia with intensive bisphosphonate therapy. J Bone Miner Res 2004; 19: 703-11.

7. Li M, Xia WB, Xing XP, et al. Benefit of infusions with ibandronate treatment in children with osteogenesis imperfecta. Chin Med J 2011; 124: 3049-53.

8. Ipach I, Kluba T, Wolf P, Pontz B, Mittag F. The influence of ibandronate treatment on bone density and biochemical bone markers in patients with osteogenesis imperfecta. Orthop Rev (Pavia) 2012; 4: e29.

9. Grenda R, Karczmarewicz E, Rubik J, et al. Bone mineral disease in children after renal transplantation in steroid-free and steroid-treated patients - a prospective study. Pediatr Transplant 2011; 15: 205-13.

10. Kutilek S, Plasilova I, Nemec V. Once-monthly oral ibandronate treatment in an adolescent with recurrent fractures and inadequately low bone mass. J Paediatr Child Health 2012; 48: 622-3.

11. Kutilek S, Plasilova I, Langer J. Ibandronate in the treatment of pediatric osteoporosis. Indian Pediatr 2016; 53: 927.

12. Karahasanovic A, Thorsteinsson AL, Bjarnason NH, Eiken P. Longterm leukopenia in a lung transplanted patient with cystic fibrosis treated with zoledronic acid: a case report. Osteoporos Int 2016; 27 : 2621-5.

13. van der Klauw MM, Goudsmit R, Halie MR, van't Veer MB, Herings RM, Wilson JH, Stricker BH. A population-based case-cohort study of drug-associated agranulocytosis. Arch Intern Med 1999; 159: 369-74.

14. Hunt KA, Resnick MP. Clomipramine-induced agranulocytosis and its treatment with G-CSF. Am J Psychiatry 1993; 150: 522-3.

15. Burke MS, Josephson A, Lightsey A. Combined methylphenidate and imipramine complication. J Am Acad Child Adolesc Psychiatry 1995; 34: 403-4. 